\title{
Improvements in Match-Related Physical Performance of Professional Soccer Players After the Application of an on-Field Training Program for Hamstring Injury Rehabilitation
}

\author{
Sergio Jiménez-Rubio, Archit Navandar, Jesús Rivilla-García, Víctor Paredes-Hernández, and \\ Miguel-Ángel Gơmez-Ruano
}

\begin{abstract}
Context: Although there are multiple, validated return-to-play programs following hamstring strain injuries, no studies have evaluated their changes in match performance parameters. Objectives: The aim of this study was twofold as follows: (1) to determine the changes in match-based physical performance parameters in professional soccer players before and after sustaining a hamstring strain injury and undergoing a soccer-specific rehabilitation program and (2) to observe the progress of these performance parameters 6 to 10 weeks after the player returned from injury. Design: Prospective, quasi-experimental longitudinal study. Setting: Soccer playing and training grounds. Participants: Nineteen players suffering a hamstring strain injury from 2 male professional teams playing in the Spanish professional football league (La Liga) were followed during the 2015-2016, 2016-2017, and 2017-2018 seasons. Intervention: Participation in on-field training program following a hamstring injury. Main Outcome Measures: Match global positioning system data were collected in the following stages: prior to injury (PRE), after return to play (RTP), program, and 6 to 10 weeks following RTP (C2). Peak velocities and distances ran at sprint velocities showed most likely improvements in C2 versus PRE, and very likely improvements in RTP versus PRE. Results: The distances ran at high and very high intensities, the average velocity, and work-to-rest ratio showed very likely improvements in C2 versus RTP and likely improvements in RTP versus PRE. Likely improvements were observed for all variables in C2 versus RTP. The authors' results showed an improvement of physical performance during competitive match after RTP, compared with PRE. There was a steady progression in the progress, and in 8 months following RTP, there was no injury reported in the players. Conclusions: The current findings may indicate that the hamstring muscle complex not only recovered completely from the injury but could also withstand a greater training and match load reducing the risk of reinjury.
\end{abstract}

Keywords: reinjury, reconditioning, GPS, biceps femoris, football, return to play

Soccer is a sport that places high and very specific physiological and technical demands on the players. Although a player can cover about 9 to $11 \mathrm{~km} /$ game on average, ${ }^{1-4}$ these actions are intermittent in nature ${ }^{5}$ and based on irregular and complex patterns that involve accelerations and decelerations in different directions and during short time periods. These performances require a great stability of lower limb and hamstring muscle complex in order to act and react according to the match constraints. Such intermittent actions can be split into different interval regimens based on the velocity thresholds $^{6}$ : high-intensity runs $(14.4-19.8 \mathrm{~km} / \mathrm{h})$, very high-intensity runs (19.9-25.1 km/h), and sprint (over $25.1 \mathrm{~km} / \mathrm{h}$ ). ${ }^{7}$ Although the distances run at higher velocities are progressively lower as the velocity ranges increase, ${ }^{8}$ the available research has suggested that the reaching peak velocities and the distance covered at very high intensities are crucial in soccer. ${ }^{3}$ At these velocities, the activation and force production of hamstring muscles become important. ${ }^{9}$

The hamstring muscle complex has been shown to play a predominant role in increasing and reaching peak sprint speeds. ${ }^{10}$ At these velocities, there is a greater increase in the stride frequency

Jiménez-Rubio, Rivilla-García, and Gómez-Ruano are with the Faculty of Sport Science, Universidad Politécnica de Madrid, Madrid, Spain. Jiménez-Rubio is also with Getafe CF, Getafe, Madrid, Spain. Navandar is with the Faculty of Sport Science, Universidad Europea de Madrid, Madrid, Spain. Paredes-Hernández is with the Faculty of Sport Science, Camilo José Cela University, Madrid, Spain. Navandar (archit.navandar@universidadeuropea.es) is corresponding author. compared with stride length, ${ }^{11}$ and this is due to increased propulsive backward movements in the lower limb as a result of greater horizontal forces where the hamstrings play a key role. ${ }^{9}$ It is also important to note that when the players perform high velocities, the hamstring muscle complex is most susceptible to an injury. ${ }^{12}$ They are believed to occur predominantly during late swing ${ }^{13}$ or stance phase $\mathrm{e}^{14}$ and are among the most frequent noncontact injuries in soccer. ${ }^{15,16}$ Hence, a quantification of the distances run at the highvelocity profiles mentioned previously, along with the peak and average velocities of the soccer players, could indicate the load on the hamstring muscle complex. A comparison of these parameters before and after an injury could be used to determine the success of the return-to-play (RTP) process. These parameters can be easily obtained from global positioning system (GPS) units attached to players. In particular, the recent and widely use of GPS devices monitors the player's performance during training sessions and competitions, ${ }^{17}$ recording various parameters. This information could help to control the progress of a player's performance during a rehabilitation process and then to enhance the key parameters that may indicate the correct period when RTP. ${ }^{18}$

Although the derived data have been used to determine player external workloads ${ }^{19}$ and physical performance, ${ }^{3}$ it has increasingly been used for injury prevention purposes as well. ${ }^{20}$ One of the key parameters that GPS generates and provides is data of the work-torest (WTR) ratio, which is the ratio of the distance covered by the player above $7 \mathrm{~km} / \mathrm{h}$ (running or sprinting) to the distance covered below $7 \mathrm{~km} / \mathrm{h}$ (walking). This parameter can help interpret the actual 
physical exertion of the player and give meaningful information about the adequacy of workloads in training and competition. Different authors have validated RTP criteria following hamstring strain injuries, ${ }^{21}$ but no one has used performance parameters from competition to evaluate the change that an intervention program can bring in performance parameters.

According to this rationale, the aim of this study was twofold as follows: (1) to determine the changes in match-based physical performance parameters in professional soccer players before and after sustaining a hamstring strain injury and undergoing a soccerspecific rehabilitation program and (2) to observe the progress of these performance parameters 6 to 10 weeks after the player returned from injury. The hypothesis was that the injured player registered similar values of physical performance parameters during postinjury period compared with preinjury (PRE) situation.

\section{Methods}

\section{Study Design}

A prospective, quasiexperimental longitudinal study was used, in which all participants having suffered a hamstring injury, participated in the proposed rehabilitation and retraining program with GPS measurements of their efforts and movements being recorded during training and in-competition matches.

\section{Participants}

Players from 2 male professional teams belonging to the Spanish professional football league (La Liga) were followed during the 2015-2016, 2016-2017, and 2017-2018 seasons, and those who satisfied the established criteria (Table 1) were included in this study.

A total of 22 male football players met the inclusion criteria proposed during the period of the study. One player chose to perform his rehabilitation externally and then chose not to participate in the study. The remaining athletes, the researcher, and the club signed an informed consent detailing the research. After recovering from the injury, 2 players did not play more than 45 minutes in matches 6 to 10 weeks after returning to competition due to technical decisions of the coaching staff, leaving the final sample in 19 players $(\mathrm{n}=19$; age 24.23 [5.36] y; height 179.87 [7.21] cm; body mass $74.78[4.09] \mathrm{kg}$ ). The entire data collection procedure was approved by the local ethics committee of the Universidad Politécnica de Madrid that participated in the study.

\section{Data Collection}

Each player's movement for matches were tracked using a 5-Hz SPI ProX GPS device (GPS Sport ${ }^{\circledR}$, Fishwick, Australia; accuracy: distance coefficient of variation $[\mathrm{CV}]=0.14 \%-3.73 \%$, velocity $\mathrm{CV}=4.22 \%-9.52 \%$; reliability: distance $\mathrm{CV}=0.34 \%-3.81 \%$, velocity: $\mathrm{CV}=3.19 \%-6.95 \%) .{ }^{23} \mathrm{PRE}$ baseline GPS data of a player were collected during the last match prior to when he suffered an injury, where the player had completed at least 45 minutes of the match. ${ }^{24}$ When a player suffered a hamstring strain injury, which was clinically diagnosed with the help of magnetic resonance imaging (MRI), he underwent percutaneous needle electrolysis. ${ }^{25}$ The electrolysis was performed 48 hours after suffering the injury under ultrasound guidance on the muscle injury using an intensity of $2 \mathrm{~mA}$ during 3 seconds and was repeated 5 times. ${ }^{26}$ The rehabilitation program began the following day. The rehabilitation program was divided into indoor and outdoor sessions. The player first participated in the indoor rehabilitation that began with controlled mobilizations of the hip and knee; proceeding to controlled dynamic displacements in the sagittal and frontal plane, where the velocity and resistance were gradually increased; and finally, the player performed unilateral strengthening exercises and drills which involved concentric-eccentric activation of the hamstrings and gluteus maximus of the injured limb. ${ }^{27}$ After a period of 6 to 7 days (based on the player's response to the previously mentioned movements and in the absence of pain while performing the exercises), the player progressed to a soccer-specific on-field 13item rehabilitation program. ${ }^{27}$ The drills incorporated repeated sprint abilities, neuromuscular control of the core and lower limbs, reeducation and retraining of acceleration-deceleration patterns, and tactical rehabilitation based on player positions. The drills were designed to be completed in a progressive manner as they were arranged in an increasing order of complexity. The player progressed from performing drills at aerobic conditions onto drills at anaerobic conditions, greater distances covered at higher velocities toward the end of the program, and a greater emphasis was placed on decisionmaking skills toward the end of the program as the uncertainty in the drills increased. ${ }^{27}$ The entire rehabilitation process was supervised by the rehabilitation fitness coach of each team and monitored through GPS devices worn by the players. Only when a drill was completed successfully, did the player proceed to the next drill. The player was declared to fit to train with the group after all the drills have successfully been repeated for 2 days. ${ }^{27}$ When the player was match-fit and returned to competition (different players had different timelines, range of days between the index injury and RTP: 16-26 d), GPS data were collected from the match (RTP). Another data point collection was determined when the player played a minimum of 45 minutes ${ }^{24} 6$ to 10 weeks after RTP $(\mathrm{C} 2)$. This period of 6 to 10 weeks was chosen for a variety of reasons. First, epidemiological studies have shown that more than $50 \%$ of reinjuries occurred within 25 days after the RTP following the index

\section{Table 1 Inclusion and Exclusion Criteria for Players in the Study}

\section{Inclusion criteria}

- Professional football players who belonged to the investigated clubs during 1 or more of the seasons 2015-2016/2016-2017/2017-2018.

- Players who sustained a grade IIb hamstring strain injury ${ }^{22}$ that was clinically diagnosed and confirmed through magnetic resonance imaging and/or musculoskeletal ultrasound.

- Players who chose to participate in the proposed intervention program put forth by the investigators.

\section{Exclusion criteria}

- Any player who does not play a minimum of 45 min after injury due to technical decisions of the coach.

- Any player who participates in alternative or additional rehabilitation programs to the one offered by the researchers.

- Any player who suffered any type of illness or injury that could lead to the alteration of the rehabilitation process, during the research period. 
injury. ${ }^{28}$ Hence, keeping this in mind, a minimum period of 6 weeks was chosen. Second, the head coach made the decision of when the player would play a match and how long he would play in the competitive match. Finally, the scheduling of matches (as determined by the national league, UEFA and FIFA) also affected this decision. Frequent MRIs of the injured muscle were taken during the entire rehabilitation and postrehabilitation phases to verify the muscle structure postinjury. ${ }^{28}$

\section{Data Processing}

The Team AMS software (version 2.0; GPS Sport ${ }^{\circledR}$ ) was used to extract GPS data. The following variables were extracted: distance per minute $(\mathrm{m} / \mathrm{min})$ at high intensities (14.4-19.7 km/h, Dist_V1); at very high intensities $(19.8-25.1 \mathrm{~km} / \mathrm{h}$, Dist_V2); and at sprint velocities $(>25.1 \mathrm{~km} / \mathrm{h}, \quad \text { Dist_V3 })^{29}$; the average speed (Avg_Speed, km/h); peak speed (Max_Speed, km/h); and WTR_Ratio (distance covered $>7.0 \mathrm{~km} / \mathrm{h} /$ distance covered $\leq 7.0 \mathrm{~km} / \mathrm{h}$ ) ${ }^{24}$

\section{Statistical Analysis}

The selected GPS variables were natural log transformed and satisfied the Kolmogorov-Smirnov test for normality. ${ }^{30}$ To compare the effect of the intervention program on the performance variables, a mixed linear model (repeated measures) was constructed, with the match (PRE, RTP, and C2) used as a fixed effect and the player as a random effect. A 2 SD difference between variables was used to determine the magnitude-based inferences ${ }^{30}$ and were standardized, and effect sizes were calculated to determine small; moderate; and large differences (threshold limits: 0.2, small; 0.6, moderate; and 1.2, large) in the performance variables in the matches. ${ }^{31,32}$ All the calculations were carried out in SPSS (version 24; IBM Corp, Armonk, NY), and statistical significance was set at $\alpha=.1$. (A confidence interval of $90 \%$ was used.)

\section{Results}

Following an injury to the hamstrings, the players returned to play a competitive game in 22.42 (2.31) days. Significant differences were observed in the different physical parameters measured during the three instances (Table 2). For Dist_V1, there were small improvements between PRE (17.45 [2.96] $\mathrm{m} / \mathrm{min})$ and RTP (19.35 [4.82] $\mathrm{m} / \mathrm{min}, P=.10)$ and RTP and C2 (20.92 [4.28] $\mathrm{m} / \mathrm{min}, P=.04)$, respectively. However, a moderate improvement $(P=.001)$ between PRE and C2 was found (Figure 1). With respect to Dist_V2, small differences were observed when comparing PRE (19.35 [4.82] m/min) and RTP (9.3 [3.26] m/min, $P=.001)$; PRE and C2 (10.59 [3.49] $\mathrm{m} / \mathrm{min}, P<.001)$; and between RTP and C2 ( $P=.17$; Figures 1-3). Similarly, for Dist_V3, a moderate improvement was noted when comparing
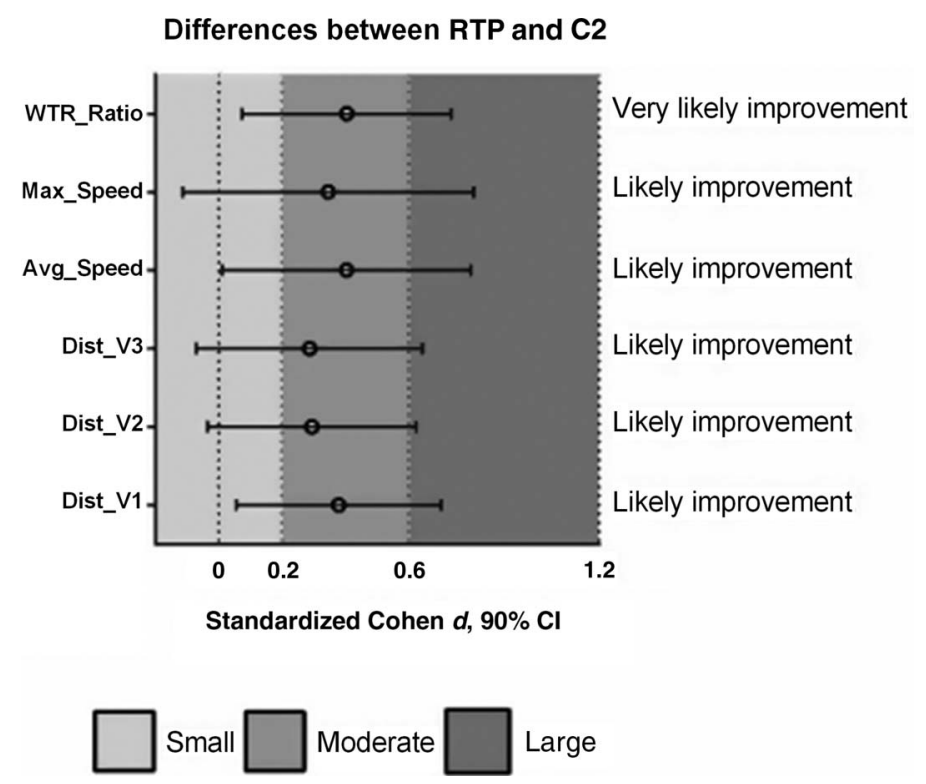

Figure 1 - Standardized differences based on magnitudes on comparing data postinjury at RTP and C2. C2 indicates 6- to 8-week postcompetition; CI, confidence interval; Dist_V1, distance per minute at high intensities; Dist_V2, distance per minute at very high intensities; Dist_V3, distance per minute at sprint velocities; RTP, return to play; WTR, work to rest.

data at C2 $(3.33[1.36] \mathrm{m} / \mathrm{min})$ with PRE $(2.05$ [1.14] $\mathrm{m} / \mathrm{min}$, $P<.001)$ and small improvements noted for the other comparisons $(P<.001$ for PRE vs RTP and $P=.25$ for RTP vs C2; Figures $1-3)$.

For Max_Speed, moderate improvements were observed in RTP (30.88 [1.05] km/h, $P<.001)$ and C2 (31.41 [1.02] km/h, $P<.001)$ compared with PRE $(29.49[2.00] \mathrm{km} / \mathrm{h})$ and small improvements in the $\mathrm{C} 2$ value compared with that at RTP $(P=.32$; Figures 1-3). While for Avg_Speed, small improvements were noted for successive measures $(P=.24$ for PRE vs RTP, $P=.09$ for RTP vs C2, and $P=.001$ for PRE vs C2; Figures $1-3$ ).

In the case of WTR_Ratio, almost similar values were obtained for PRE (1.59 [0.29]) and RTP (1.61 [0.36]) values $(P=1.000)$; however, C2 (1.72 [0.32]) showed small improvements when compared with PRE $(P=.02)$ and RTP $(P=.03$; Figures 1-3).

\section{Discussion}

This research aimed to determine the progress of velocity-based match performance parameters produced with professional soccer players who suffered a hamstring strain injury. As was argued, the values of the performance-based parameters would not be different

Table 2 Descriptive Data of Variables in the 3 Moments (Mean [SD])

\begin{tabular}{lccc}
\hline Variable & PRE & RTP & C2 \\
\hline Distance run at high intensities, m/min & $17.45(2.96)$ & $19.35(4.82)$ & $20.92(4.28)$ \\
Distance run at very high intensities, m/min & $7.25(2.76)$ & $9.3(3.26)$ & $10.59(3.49)$ \\
Distance run at sprint velocities, m/min & $2.05(1.14)$ & $2.99(1.58)$ & $3.33(1.36)$ \\
Average speed, $\mathrm{km} / \mathrm{h}$ & $6.70(0.64)$ & $6.89(0.61)$ & $7.15(0.57)$ \\
Maximum speed, $\mathrm{km} / \mathrm{h}$ & $29.49(2.00)$ & $30.88(1.05)$ & $31.41(1.02)$ \\
Work-to-rest ratio & $1.59(0.29)$ & $1.61(0.36)$ & $1.72(0.32)$ \\
\hline
\end{tabular}

Abbreviations: C2, 6 to 10 weeks after RTP; PRE, preinjury; RTP, return to play. Note: Match performance data expressed in 3 moments: C2, PRE, and RTP. 


\section{Differences between PRE and RTP}

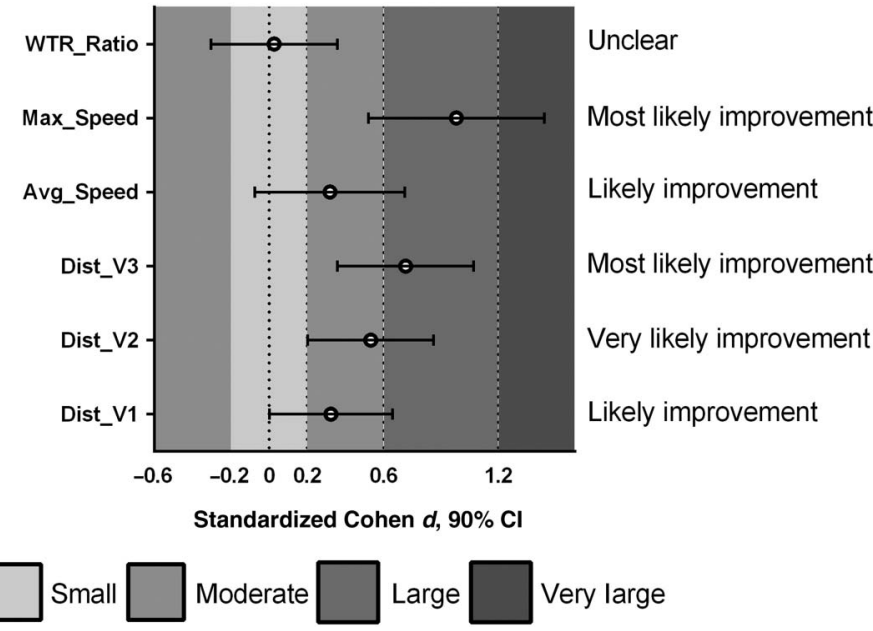

Figure 2 - Standardized differences based on magnitudes on comparing data PRE to RTP. CI indicates confidence interval; Dist_V1, distance per minute at high intensities; Dist_V2, distance per minute at very high intensities; Dist_V3, distance per minute at sprint velocities; PRE, preinjury; RTP, return to play; WTR, work to rest.
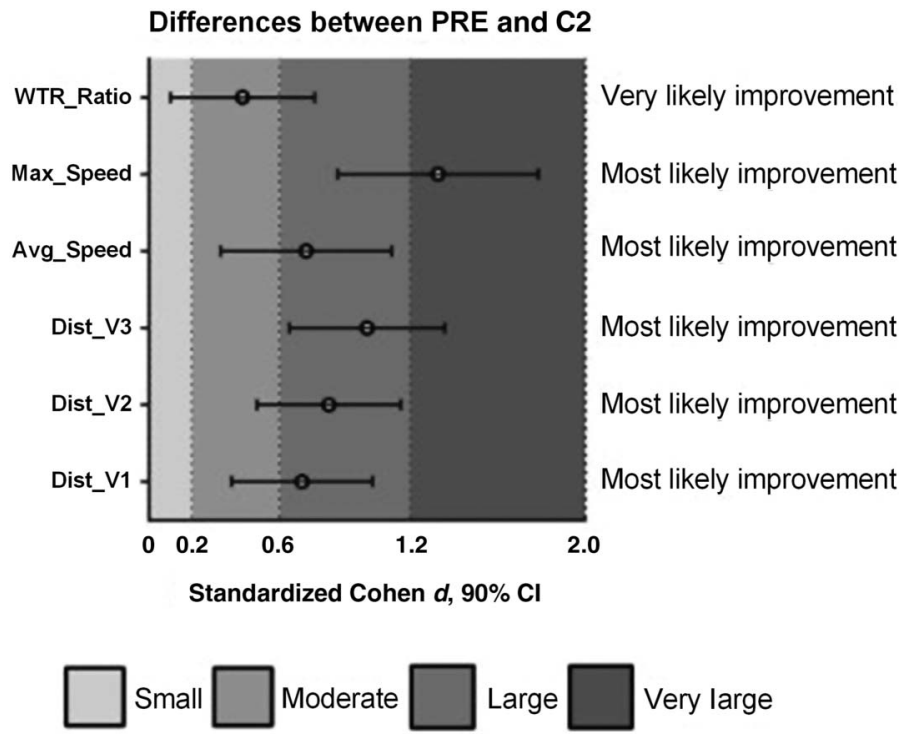

Figure 3 - Standardized differences based on magnitudes on comparing data PRE to $\mathrm{C} 2$. C2 indicates 6- to 8-week postcompetition; CI, confidence interval; Dist_V1, distance per minute at high intensities; Dist_V2, distance per minute at very high intensities; Dist_V3, distance per minute at sprint velocities; PRE, preinjury; WTR, work to rest.

PRE and postinjury; ${ }^{18}$ however, we can reject the hypothesis presented as the results of the research showed an improvement in performance in competition compared with PRE data. Also, a steady progression in the progress of these parameters was found, indicating that the hamstring muscle complex not only recovered completely from the injury but could also withstand a greater training and match load.

The most important improvements were observed in the peak speed (Max_Speed) and the distance run per minute at sprint speeds (Dist_V3). These variables showed moderate to large improvements following the intervention at RTP and also at C2, when compared with PRE data. Research has shown that as the velocity increases above $25 \mathrm{~km} / \mathrm{h}$, it is the stride frequency that increases, and there is little increase in stride length. ${ }^{11}$ As a result, the player pushes the ground more frequently, ${ }^{33}$ resulting in the increase of the anteroposterior ground reaction forces. ${ }^{34}$ At these velocities, the thigh muscles that are responsible for the increase in ground reaction forces instead of the gastrocnemius or the tibialis anterioris, which generates ground reaction forces at lower speeds. ${ }^{33}$ As a consequence, there is an increase in the biomechanical demands on the lower-limb muscles of the hip, ${ }^{33}$ especially the hamstring and gluteal muscles that are responsible for producing horizontal forces at the end of the stance phase with the extension of the hip. ${ }^{9,35}$ These muscles are considered as hip-extensor muscles and are key during the pushing off the ground phase. ${ }^{35}$ The results from this study indicate that the hamstring and gluteal muscles were able to withstand greater loads and that the player had a greater capacity to run greater distances at sprint velocities and reach higher peak velocities.

The improvement of the physical performance parameters at $\mathrm{C} 2$ highlights the importance of match fitness while dealing with sprint-related variables. In a match, a player performs 7 to 61 sprints depending on the position. ${ }^{36,37}$ The incorporation of sprint training, as a part of soccer training, not only improves sprint performance in matches but also works as an injury prevention strategy. ${ }^{17}$ A steady increase in the peak (sprint) velocity and the distances run at maximal and submaximal speeds from RTP to C2 indicate that the player could tolerate increasing biomechanical loads and, as a result, steadily improve performance as well. ${ }^{27,38}$ Another important aspect to consider is that none of the players who participated in the program suffered a reinjury within 8 months after participating in this program, indicating its effectiveness.

The small to moderate improvements in Dist_V2 reinforces the success of the intervention program, both at RTP and at C2. A player performs greater distances at these velocities than at sprint velocities; therefore, an improvement in this variable not only suggests an improvement in overall physical performance of the player but also strengthens the hamstring muscles against reinjury as they can get injured at submaximal speeds as well. ${ }^{12}$ Recent studies show that the hamstring muscles, postinjury, first need to generate forces at lower velocities sustained over a particular period of time, and only then they can generate the explosive forces required to withstand sprint velocities. ${ }^{39}$

The regular participation of the player in matches and training after returning from injury enabled the player to have greater improvements in Dist_V1 and Avg_Speed at C2, than at RTP, when compared with PRE. The absence of a player from regular training not only affects the injured muscle but can also affect the surrounding structures, which could have an adverse effect on the on-field performance of the player. The rehabilitation program ${ }^{27}$ focused on developing lower-body strength, movements in sagittal and frontal plane ${ }^{37}$ including high-speed drills such as repeated sprint abilities, and football-specific tactical work. ${ }^{3}$ The improvements of the player in these physical performance variables show that the intervention program focused not only on the injured muscle function but also on the entire lower-body structures. The use of GPS in the training drills ${ }^{40}$ permitted objective criteria to be used to determine RTP. ${ }^{21}$

When comparing the data at RTP and C2, statistical analysis showed that the improvement was unclear (Figure 2). However, if one was to compare the data to previous injury data at these 2 instances (Figures 1 and 3), the improvement appears to be trivial 
to small. This reinforces the importance of match fitness and participation in competition, as the variables that showed a steady improvement. The results also indicate the player not only had a better control after RTP but also appeared to have a lower fear of reinjury. ${ }^{41}$

It is important to note that there was a large variation in the data related to the velocity-related variables. This finding can be explained by the fact that the study did not segregate the players by playing position ${ }^{4}$ and quality of opposition, ${ }^{42}$ adding to the fact that the match data were collected when the player completed a minimum of 45 minutes of match play. ${ }^{24}$ Another important issue to consider, while interpreting the average velocity data, is that this represented the average of all actions performed by the player, not just at high intensities and sprints. This can be seen by the trivial to moderate differences in the WTR_Ratio (Figure 1), which represented a ratio of the distance run by the player above $7 \mathrm{~km} / \mathrm{h}$ to the distance run under $7 \mathrm{~km} / \mathrm{h}$. A player normally performs most of the movements under $14 \mathrm{~km} / \mathrm{h}$, and this variable might not be a determinant of player performance. However, it is important to highlight that at $\mathrm{C} 2$, the player was capable of generating greater volumes at all intensities above $7 \mathrm{~km} / \mathrm{h}$, which appeared to contribute to an improvement in variables related to higher velocities. ${ }^{43}$ This can be corroborated by comparing data of acceleration patterns in these instances in future studies.

One of the limitations of this study was that all the data were registered through a GPS device; that is, no different biomechanical or physiological tests (e.g., data from a force platform) were registered to identify exactly the measurement of lower-body strength changes. Another limitation of this study was that data from injured players were not compared with that of uninjured players. However, considering that the 19 players of this study belonged to 2 clubs over 3 seasons and were not injured at the same time, such a comparison would be difficult to be carried out. Future studies could incorporate accelerometer data also gathered by the GPS apparatus worn by the players. Further, only participants who had a tear classified as a grade IIb muscle injury ${ }^{22}$ were considered in this study. Players having different types of grade II injuries (or grade I or grade III) to the hamstring muscle group were not included in the study. Therefore, future studies could explore the success in the implementation of this program in such cases.

\section{Conclusions}

Similar to other studies which have shown that incorporating lengthened state eccentric training might help reduce the risk of reinjury in the hamstrings, ${ }^{44}$ but this study has shown how a sportspecific, rehabilitation program not only prevented injuries but also improved performance at high velocities. The performance of the players showed a steady progress 6 to 10 weeks following RTP, highlighting the positive effects of the program, as the player could withstand the match loads and could improve performance with regular match practice and competition.

\section{References}

1. Bradley PS, Carling C, Gomez Diaz A, et al. Match performance and physical capacity of players in the top three competitive standards of English professional soccer. Hum Mov Sci. 2013;32:808-1150. PubMed ID: 23978417 doi:10.1016/j.humov.2013.06.002

2. Dellal A, Chamari K, Wong DP, et al. Comparison of physical and technical performance in European soccer match-play: FA Premier
League and La Liga. Eur J Sport Sci. 2011;11(1):51-59. doi:10.1080/ 17461391.2010.481334

3. Mallo J, Mena E, Nevado F, Paredes V. Physical demands of top-class soccer friendly matches in relation to a playing position using global positioning system technology. J Hum Kinet. 2015;47(1):179-188. doi:10.1515/hukin-2015-0073

4. Rivilla-García J, Calvo LC, Jiménez-Rubio S, et al. Characteristics of very high intensity runs of soccer players in relation to their playing position and playing half in the 2013-14 Spanish La Liga season. J Hum Kinet. 2019;66:213-222. doi:10.2478/hukin-20180058

5. Rampinini E, Sassi A, Morelli A, Mazzoni S, Fanchini M, Coutts AJ. Repeated-sprint ability in professional and amateur soccer players. Appl Physiol Nutr Metab. 2009;34(6):1048-1054. PubMed ID: 20029513 doi:10.1139/H09-111

6. Gaudino P, Alberti G, Iaia FM. Estimated metabolic and mechanical demands during different small-sided games in elite soccer players. Hum Mov Sci. 2014;36:123-133. PubMed ID: 24968370 doi:10. 1016/j.humov.2014.05.006

7. Stevens TG, de Ruiter CJ, Twisk JW, Savelsbergh GJ, Beek PJ. Quantification of in-season training load relative to match load in professional Dutch Eredivisie football players. Sci Med Football. 2017;1(2):117-125. doi:10.1080/24733938.2017.1282163

8. Di Salvo V, Baron R, Tschan H, Calderón Montero FJ, Bachl N, Pigozzi F. Performance characteristics according to playing position in elite soccer. Int J Sports Med. 2007;28:222-227. PubMed ID: 17024626 doi:10.1055/s-2006-924294

9. Morin JB, Gimenez P, Edouard P, et al. Sprint acceleration mechanics: the major role of hamstrings in horizontal force production. Front Physiol. 2015;6:404. PubMed ID: 26733889 doi:10.3389/fphys. 2015.00404

10. Schache AG, Brown NAT, Pandy MG. Modulation of work and power by the human lower-limb joints with increasing steady-state locomotion speed. J Exp Biol. 2015;218(pt 15):2472-2481. PubMed ID: 26056240 doi:10.1242/jeb.119156

11. Dorn TW, Schache AG, Pandy MG. Muscular strategy shift in human running: dependence of running speed on hip and ankle muscle performance. J Exp Biol. 2012;215(pt 11):1944-1956. PubMed ID: 22573774 doi:10.1242/jeb.064527

12. Schache AG, Dorn TW, Blanch PD, Brown NA, Pandy MG. Mechanics of the human hamstring muscles during sprinting. Med Sci Sports Exerc. 2012;44(4):647-658. PubMed ID: 21912301 doi:10.1249/MSS.0b013e318236a3d2

13. Chumanov ES, Heiderscheit BC, Thelen DG. Hamstring musculotendon dynamics during stance and swing phases of high-speed running. Med Sci Sports Exerc. 2011;43(3):525-532. PubMed ID: 20689454 doi:10.1249/MSS.0b013e3181f23fe8

14. Orchard JW. Hamstrings are most susceptible to injury during the early stance phase of sprinting. Br J Sports Med. 2012;46(2):88-89. PubMed ID: 21930513 doi:10.1136/bjsports-2011-090127

15. Ekstrand J, Waldén $M$, Hägglund $M$. Hamstring injuries have increased by $4 \%$ annually in men's professional football, since 2001: a 13-year longitudinal analysis of the UEFA Elite Club injury study. Br J Sports Med. 2016;50(12):731-737. PubMed ID: 26746908 doi:10.1136/bjsports-2015-095359

16. Noya Salces J, Gómez-Carmona PM, Gracia-Marco L, MolinerUrdiales D, Sillero-Quintana M. Epidemiology of injuries in first division Spanish football. J Sports Sci. 2014;32(13):1263-1270. PubMed ID: 24787731 doi:10.1080/02640414.2014.884720

17. Malone S, Owen A, Mendes B, Hughes B, Collins K, Gabbett TJ. High-speed running and sprinting as an injury risk factor in soccer: can well-developed physical qualities reduce the risk? J Sci Med 
Sport. 2018;21(3):257-262. PubMed ID: 28595870 doi:10.1016/j. jsams.2017.05.016

18. van der Horst N, Backx F, Goedhart EA, Huisstede BM. Return to play after hamstring injuries in football (soccer): a worldwide Delphi procedure regarding definition, medical criteria and decision-making. Br J Sports Med. 2017;51(22):1583-1591. PubMed ID: 28360143 doi:10.1136/bjsports-2016-097206

19. Gabbett TJ, Whyte DG, Hartwig TB, Wescombe H, Naughton GA. The relationship between workloads, physical performance, injury and illness in adolescent male football players. Sports Med. 2014;44(7):989-1003. PubMed ID: 24715614 doi:10.1007/s40279014-0179-5

20. Bowen L, Gross AS, Gimpel M, Li F-X. Accumulated workloads and the acute:chronic workload ratio relate to injury risk in elite youth football players. Br J Sports Med. 2017;51(5):452-459. PubMed ID: 27450360 doi:10.1136/bjsports-2015-095820

21. Zambaldi M, Beasley I, Rushton A. Return to play criteria after hamstring muscle injury in professional football: a Delphi consensus study. Br J Sports Med. 2017;51(16):1221-1226. PubMed ID: 28246078 doi:10.1136/bjsports-2016-097131

22. Pollock N, James SL, Lee JC, Chakraverty R. British athletics muscle injury classification: a new grading system. Br J Sports Med. 2014;48(18):1347-1351. PubMed ID: 25031367 doi:10.1136/ bjsports-2013-093302

23. Koklu Y, Arslan Y, Alemdaroglu U, Duffield R. Accuracy and reliability of SPI Pro $\mathrm{X}$ global positioning system devices for measuring movement demands of team sports. J Sports Med Phys Fitness. 2015;55(5):471-477. PubMed ID: 25303067

24. Suarez-Arrones L, Torreno N, Requena B, et al. Match-play activity profile in professional soccer players during official games and the relationship between external and internal load. J Sports Med Phys Fitness. 2015;55(12):1417-1422. PubMed ID: 25289717

25. Mattiussi G, Moreno C. Treatment of proximal hamstring tendinopathy-related sciatic nerve entrapment: presentation of an ultrasound-guided "Intratissue Percutaneous Electrolysis" application. Muscles Ligaments Tendons J. 2016;6(2):248. PubMed ID: 27900300 doi:10.32098/mltj.02.2016.13

26. Valera-Garrido F, Minaya-Muñoz F, Medina-Mirapeix F. Ultrasoundguided percutaneous needle electrolysis in chronic lateral epicondylitis: short-term and long-term results. Acupunct Med. 2014;32(6):446-454. PubMed ID: 25122629 doi:10.1136/acupmed-2014-010619

27. Jiménez-Rubio S, Navandar A, Rivilla-García J, Paredes-Hernández V. Validity of an on-field readaptation program following a hamstring injury in professional soccer. J Sport Rehabil. 2019;28(6):jsr.20180203.

28. Wangensteen A, Bahr R, Van Linschoten R, et al. MRI appearance does not change in the first 7 days after acute hamstring injury: a prospective study. Br J Sports Med. 2017;51(14):1087-1092. PubMed ID: 28031188 doi:10.1136/bjsports-2016-096881

29. Owen A, Djaoui L, Newton M, Malone S, Mendes B. A contemporary multi-modal mechanical approach to training monitoring in elite professional soccer. Sci Med Football. 2017;1(3):216-221. doi:10. 1080/24733938.2017.1334958

30. Hopkins W, Marshall S, Batterham A, Hanin J. Progressive statistics for studies in sports medicine and exercise science. Med Sci Sports
Exerc. 2009;41(1):3-13. PubMed ID: 19092709 doi:10.1249/MSS. 0b013e31818cb278

31. Cohen J. A power primer. Psychol Bull. 1992;112(1):155-159. PubMed ID: 19565683 doi:10.1037/0033-2909.112.1.155

32. Hopkins WG. Spreadsheets for analysis of validity and reliability. Sportscience. 2015;19:36-44.

33. Schache AG, Dorn TW, Williams GP, Brown NA, Pandy MG. Lower-limb muscular strategies for increasing running speed. J Orthop Sports Phys Ther. 2014;44(10):813-824. PubMed ID: 25103134 doi:10.2519/jospt.2014.5433

34. Tominaga R, Ishii Y, Ueda T, Kurokawa T. The effects of running speed on ground reaction forces and lower limb kinematics during single-leg stop movement. J Strength Cond Res. 2016;30(5):1224 1230. PubMed ID: 24149754 doi:10.1519/JSC.0000000000000286

35. Schuermans J, Danneels L, Van Tiggelen D, Palmans T, Witvrouw E. Proximal neuromuscular control protects against hamstring injuries in male soccer players: a prospective study with electromyography time-series analysis during maximal sprinting. Am J Sports Med. 2017;45(6):1315-1325. PubMed ID: 28263670 doi:10.1177/ 0363546516687750

36. Di Salvo V, Baron R, Gonzalez-Haro C, Gormasz C, Pigozzi F, Bachl N. Sprinting analysis of elite soccer players during European Champions League and UEFA cup matches. J Sports Sci. 2010;28(14):14891494. PubMed ID: 21049314 doi:10.1080/02640414.2010.521166

37. Taylor JB, Wright AA, Dischiavi SL, Townsend MA, Marmon AR. Activity demands during multi-directional team sports: a systematic review. Sports Med. 2017;47(12):2533-2551. PubMed ID: 28801751 doi:10.1007/s40279-017-0772-5

38. Buckthorpe M, Gimpel M, Wright S, Sturdy T, Stride M. Hamstring muscle injuries in elite football: translating research into practice. Br J Sports Med. 2018;52(10):628-629. doi:10.1136/bjsports-2017097573

39. Mendiguchia J, Martinez-Ruiz E, Morin JB, et al. Effects of hamstring-emphasized neuromuscular training on strength and sprinting mechanics in football players. Scand J Med Sci Sports. 2015;25(6): e621-e629. doi:10.1111/sms.12388

40. Reid LC, Cowman JR, Green BS, Coughlan GF. Return to play in elite rugby union: application of global positioning system technology in return-to-running programs. J Sport Rehabil. 2013;22(2):122_ 129. PubMed ID: 23238265 doi:10.1123/jsr.22.2.122

41. Chao-Jung H, Adam M, Steven ZG, Terese LC. Fear of reinjury in athletes: implications for rehabilitation. Sports Health. 2016;9(2): 162-167.

42. Liu H, Gómez M-A, Gonçalves B, Sampaio J. Technical performance and match-to-match variation in elite football teams. J Sports Sci. 2016;34(6):509-518. PubMed ID: 26613399 doi:10.1080/02640414. 2015.1117121

43. Harnish CR, Sabo RT. Comparison of two different sprint interval training work-to-rest ratios on acute inflammatory responses. Sports Med Open. 2016;2:20. PubMed ID: 27034919 doi:10.1186/s40798016-0044-1

44. Schmitt B, Tyler T, McHugh M. Hamstring injury rehabilitation and prevention of reinjury using lengthened state eccentric training: a new concept. Int J Sports Phys Ther. 2012;7(3):333-341. PubMed ID: 22666648 